\title{
Nietzsche e a busca pelo seu leitor ideal
}

\author{
Eduardo Nasser"
}

\begin{abstract}
Resumo: Durante praticamente todo o seu itinerário filosófico, Nietzsche se preocupou com a recepção de seu pensamento, desenvolvendo coordenadas de como gostaria que os seus escritos fossem lidos. Essas coordenadas passam a cumprir uma função particularmente significativa e estratégica no período em que o filósofo concebe o projeto de um ocultamento resoluto de suas posições mais essenciais - um projeto que vai de par com a adesão ao estilo aforismático-, podendo ser dividas em duas classes: aquelas que solicitam o leitor que preserva a literalidade do texto e aquelas que estimulam o leitor a empreender uma arte de interpretação. A reunião desses dois direcionamentos fecunda a figura do leitor ideal de Nietzsche, o leitor que adentra de forma ativa na corrente de pensamentos que precede os aforismos, sem, contudo, perder de vista a letra do filósofo. Palavras-chave: leitor - recepção - filologia - interpretação - aforismo
\end{abstract}

Neste artigo, procurarei investigar as sugestões dadas por Nietzsche para os seus leitores de como ele gostaria de ser lido. Feitas ao longo de praticamente toda a produção nietzschiana de maneira esparsa e pouco sistemática, muitos podem, por certo, ver nessas sugestões nada além do reflexo de um autor preocupado com os seus leitores mais ansiosos. Isso poderia nos convencer de que elas cumprem unicamente uma propedêutica para um público restrito, um público ainda imaturo que necessita ser advertido. Contudo, eu gostaria de apresentar a hipótese de que essas sugestões não são tão banais quanto parecem, fazendo parte de uma estratégia mais

\footnotetext{
* Doutor em filosofia pela Universidade de São Paulo (USP), Brasil, membro do Grupo de Estudos Nietzsche (GEN) e do Groupe International de Recherches sur Nietzsche (GIRN). E-mail: enasser@uol.com.br.
} 
sofisticada. Pois Nietzsche não quer com elas fazer somente uma advertência oportuna, mas também apresentar regras. Isso significa que a obra nietzschiana - ou ao menos parte dela, aquela que compreende os escritos aforismáticos - não pode ser abordada como um objeto que acolhe diversos tipos de leituras sem impedimentos. Trata-se de uma obra bastante peculiar que impõe, desde si, condições para ser acessada, exigindo, enfim, um tipo de leitor ideal.

\section{O leitor filólogo.}

Diferentemente de grande parte dos filósofos, Nietzsche sempre se mostrou preocupado com o seu leitor, provavelmente antevendo a grande quantidade de controvérsias que marcaria a recepção do seu pensamento. Essa preocupação aparece pela primeira vez de uma forma explícita no prefácio de Sobre o futuro de nossos estabelecimentos de formação, quando o filósofo traz a lume um pequeno manual de como gostaria de ser lido.

O leitor do qual espero alguma coisa tem de ter três propriedades: deve ser calmo e ler sem pressa, não deve sempre privilegiar a si mesmo e intrometer a sua 'formação' (Bildung), não lhe é permitido, por fim, esperar na conclusão algo como um resultado, uma listagem (BA/ EE Prólogo I, KSA 1. 648).

Temos aí um primeiro tipo de diretriz endereçada por Nietzsche aos seus leitores. Ela tem em vista um destinatário bastante específico: o homem moderno que não sabe ler bem ${ }^{1}$. $O$ seu objetivo pode, assim, ser classificado como puramente corretivo. $\mathrm{O}$ bom leitor dos

1 Nesse sentido, vale destacar, essa primeira diretriz espelha uma preocupação de caráter educacional cuja dimensão é mais vasta. Lembremo-nos que Nietzsche planejava publicar uma obra, no contexto das suas Considerações extemporâneas, que contemplasse o problema da escrita. Cf. Nachlass/FP 1873, 29[163], KSA 7. 699.

34 I Cad. Nietzsche, São Paulo, v.I n.35, p. 33-56, 2014. 
textos nietzschianos seria aquele que toma distância dos valores cultivados na modernidade, como pressa, improbidade, utilitarismo. Conter a ansiedade é um preparo necessário para se ter a experiência de alteridade, para aprender a reconhecer o texto enquanto tal ao invés de si mesmo.

Essas instruções são reiteradas no prólogo de 1886 redigido para Aurora: esse livro, diz Nietzsche, requer o leitor que põe de lado o mau hábito de leitura adquirido nessa "época do "trabalho" (Zeitalter der 'Arbeit'), da pressa que "tudo quer logo 'terminar", e se irmana com o "lento" (M/A Prólogo 5, KSA 3. 17). Nesse momento surge uma designação para esse tipo de leitor: o leitor filólogo. Cumpre destacar que a concepção de filologia possui aqui um sentido estrito. O filólogo é o "professor da lenta leitura", aquele que, ao dar-se tempo, quer "saber da palavra" (M/A Prólogo 5, KSA 3. 17). Nietzsche realça um traço significativo de uma determinada tradição filológica - possivelmente aquela mais conectada à Sprachphilologie fundada por Hermann, e conservada por Ritschl e a escola de Bonn, que entende a filologia como crítica de texto que privilegia o estudo da linguagem ${ }^{2}-$ e define o filólogo como o leitor que preza a letra do texto, vendo-o como um fato. Nesse ponto, é importante notar que Nietzsche opõe com veemência filologia à interpretação. A filologia é a "arte de ler bem, de compreender - poder ler fatos sem falseá-los com interpretação (Interpretation)" (AC/AC 52, KSA 6. 233). No tratamento dado por Nietzsche à hermenêutica bíblica essa oposição é particularmente nítida. Os teólogos, decididos a interpretar as "palavras

2 Sobre as características da Sprachphilologie de Hermann, cf. VOGT, E. "Der Methodenstreit zwischen Hermann und Böckh und seine Bedeutung für die Geschichte der Philologie” in: FLASHAR, H., GRÜNDER, K., HORSTMANN, A. (orgs.). Philologie und Hermeneutik im 19. Jahrhundert. Zur Geschichte und Methodologie der Geisteswissenschaften. Göttingen: Vandenhoeck \& Ruprecht, 1979, pp. 103 - 121. Sobre o método veiculado pela escola filológica de Ritschl em Bonn, cf. BICKEL, E. Friedrich Ritschl und der Humanismus in Bonn: ein Beitrag zur Neugestaltung der höheren Schule in der Nord-Rheinprovinz. Bonn: Hans Scheur, 1946, pp. 22 - 28. Vale lembrar que Ritschl foi um dos grandes mestres de Nietzsche. 
Nasser, E.

das escrituras", demonstraram a sua "inaptidão para a filologia", falseando, assim, os "fatos" (AC/AC 52, KSA 6. 232). Esse "fato" ignorado pelos teólogos foi o texto. "Toda a Idade Média foi profundamente incapaz de uma explicação (Erklärung) estritamente filológica, isto é, do simplesmente querer-entender o que diz o autor" (MA I/HH I 270, KSA 2. 223) ${ }^{3}$.

O leitor filólogo é a primeira figura do leitor ideal de Nietzsche. Em antagonismo ao intérprete, essa figura requer que se atenha à literalidade do texto. É somente esse leitor que pode realizar o seu desejo de ser lido tal "como os bons filólogos de outrora liam seu Horácio" (EH/EH, Por que escrevo livros tão bons 5, KSA 6. 305). Esse esclarecimento não diz somente algo acerca da conduta que o leitor deve adotar, mas coloca em evidência informações significativas sobre a natureza do texto. Pois, se para compreendermos os textos nietzschianos basta lê-los calmamente sem se intrometer no seu andamento, i.e., lê-los como um filólogo, tudo leva a crer que o texto deve ser visto como uma unidade fechada e objetiva. Eis uma hipótese que soa bastante adequada, acima de tudo quando posta diante de algumas passagens do chamado período médio ${ }^{4}$. Numa delas, para ficarmos somente com um exemplo, deparamo-nos com a defesa que Nietzsche faz da "vida própria" da obra quando ela se desprende do seu criador, de modo que pouco importa as intenções do autor ao escrevê-la, ou se ele ainda a compreende: a obra "vive como um ser dotado de espírito e alma” (MA I/HH I 208, KSA 2. 171). Dessa forma, do leitor se espera somente uma competência lógica e gramatical. Basta, em suma, espelhar, comentar, o texto, não sendo necessário lançar mão de algum expediente que o exceda.

\section{O leitor intérprete.}

3 Cf. também: MA I/HH I 8, KSA 2. 28.

4 Cf. VM/OS 140, 156, KSA 2. 436, 442, 443.

36 | Cad. Nietzsche, São Paulo, v.I n.35, p. 33-56, 2014. 
O cenário descrito acima é, obviamente, bastante conservador e não coloca maiores obstáculos para leitores atentos. A sugestão implícita é que se ocorrem más compreensões, as causas devem ser buscadas no sujeito (o leitor) e não no objeto (o texto). Contudo, essa conclusão parcial não está em imediata concordância com uma outra importante instrução. No prólogo de Para a genealogia da moral, o filósofo circunscreve possíveis razões para que ele seja um autor de difícil compreensão e elege, dentre outras, a sua escolha pela forma aforística, donde se segue uma importante revelação.

Em outros casos, a forma aforística suscita dificuldade: ela reside em que hoje não se leva suficientemente a sério essa forma. Um aforismo, corretamente cunhado e vertido, não foi ainda "decifrado" ao ser lido; antes é preciso já começar com a sua interpretação (Auslegung), que precisa de uma arte da interpretação (Kunst der Auslegung) (...) Sem dúvida que para praticar desse modo a leitura como arte faz-se necessário algo que justamente em nossos dias está bem esquecido - e que exigirá tempo, até que minhas obras sejam "legíveis" -, para o qual é imprescindível ser quase uma vaca, e não um "homem moderno": o ruminar... (GM/GM Prólogo 8, KSA 5. 255).

Diante desse depoimento, vemos emergir uma segunda figura do leitor ideal de Nietzsche, que em alguma medida contradiz a primeira: o leitor intérprete. O filósofo o solicita nos casos de escritos aforísticos, dando a entender que a má compreensão é também um elemento constituinte dos seus escritos. É verdade que o destinatário continua sendo o mesmo (o homem moderno); porém, temos novas informações sobre o leitor e o texto. A novidade é que uma simples leitura atenta já não é mais suficiente. Para além da leitura, exige-se uma arte da interpretação. Eu gostaria de sugerir que essa exigência faz parte de uma estratégia cuidadosamente elaborada que não está em imediata e harmoniosa continuidade com as primeiras prescrições, merecendo especial atenção. 
Nasser, E.

\section{A filosofia de fachada.}

Comecemos com uma pergunta trivial: Nietzsche demonstrou a sua filosofia? Essa pergunta não é tão tola quanto parece, podendo ser justificada à luz de algumas surpreendentes considerações feitas pelo filósofo acerca da necessidade de se recear diante da demonstração.

Um eremita não crê que um filósofo - supondo que todo filósofo tenha sido antes um eremita - alguma vez tenha expresso num livro suas opiniões genuínas e últimas: não se escrevem livros para se esconder precisamente o que se traz dentro de si? - ele duvidará inclusive que um filósofo possa ter opiniões "verdadeiras e últimas", e que nele não haja, não tenha de haver, uma caverna mais profunda por trás de cada caverna - um mundo mais amplo, mais rico, mais estranho além da superfície, um abismo atrás de cada chão, cada razão, por baixo de toda "fundamentação". Toda filosofia é uma filosofia-de-fachada (Vordergrunds-Philosophie) (...) Toda filosofia também esconde uma filosofia, toda opinião é também um esconderijo, toda palavra também uma máscara (JGB/BM 289, KSA 5. 234).

Todo filósofo, ao menos todo filósofo profundo, deve estar comprometido com o ocultamente resoluto de suas posições essenciais. Esse apelo, que emerge aqui como uma norma dirigida para todo filósofo profundo, aparentemente serviu como uma diretriz pessoal para Nietzsche. Num fragmento póstumo, escrito em tom de depoimento, e que se encontra em perfeita harmonia com o teor apresentado na citação, diz Nietzsche: "Eu sei bem que prefiro mais os meus pensamentos em suspensão (Gedankenstriche) do que os pensamentos que comuniquei" (Nachlass/FP 1884 - 1885, 34[147], KSA 11. 469). Na mesma direção, pode-se ler: "Eu não estimo mais os leitores: como eu poderia escrever para leitores?... Mas eu tomo notas de mim, para mim" (Nachlass/FP 1885 - 1887, 9[188], KSA 12. 450). 
Mas o que inspira essa visão tão insólita? É cabível, antes de tudo, encontrar uma razão para tanto na conhecida desconfiança nietzschiana da linguagem. Crítico da linguagem, Nietzsche coloca-a frequentemente em antagonismo ao pensamento em toda a sua riqueza - o que deixa à mostra que o nosso filósofo conserva de algum modo aquilo que Gerber nomeou de a visão habitual sobre a relação entre linguagem e pensamento, e isto apesar de Nietzsche ter sido muito tocado por Die Sprache als Kunst ${ }^{5}$. Distinguindo os domínios do pensamento consciente (semiótico / superficial / estático) e o pensamento inconsciente (pré-linguístico / profundo / processual), o filósofo identifica uma dissimetria ${ }^{6}$. Os signos, carentes de função denotativa, cumprem finalidades utilitárias que visam a abreviar o múltiplo, nunca podendo expressar o que realmente se pensou ou se sentiu. Donde a necessidade estratégica de

5 Segundo Gerber, "a visão habitual pensa a relação entre pensamento e linguagem de uma tal maneira como opondo forma e matéria", uma visão inadequada por ignorar que o pensamento teórico "se desenvolve ao mesmo tempo na e com a linguagem" (GERBER, G. Die Sprache als Kunst. Berlin: R. Gaertners, 1885, p. 239). Mas poder-se-ia realmente opor Nietzsche a Gerber? Afinal de contas, em muitas anotações redigidas entre 1872 - 1873, principalmente no seu curso sobre retórica e em Sobre verdade e mentira no sentido extra-moral, Nietzsche se beneficia, como se sabe, da teoria da linguagem de Gerber. Restaria examinar até que ponto esse laço persistiu na sua filosofia tardia, uma tarefa que não levarei adiante nesse trabalho. O que se pode dizer é que, aparentemente, nesse momento Nietzsche não aprova de maneira irrestrita o projeto gerberiano - mas também encabeçado por Hamann, Haym, Prantl, Harms e Buse -, de uma crítica da linguagem, ou uma crítica da razão impura, cujo efeito mais notável é substituir o pensamento puro pela linguagem. Pois ainda que identifique o pensamento consciente com a linguagem - o que certamente o afasta do idealismo transcendental, o principal adversário dos filósofos da linguagem -, Nietzsche possui uma concepção mais vasta de pensamento, inconsciente, que não está em concordância com o primeiro plano.

6 "Exprimimos nossos pensamentos sempre com palavras que se acham à mão. Ou para exprimir toda a minha suspeita: a cada instante temos apenas o pensamento para o qual as palavras nos estão à mão, que conseguem exprimi-lo aproximadamente" (M/A 257, KSA 3. 257). "Por um longo período o pensamento consciente foi tido como o pensamento em absoluto: apenas agora começa a raiar para nós a verdade de que a atividade do nosso espírito ocorre, em sua maior parte, de forma inconsciente e não sentida" (FW/GC 333, KSA 3. 559). "O pensamento que se torna consciente é a menor parte, digamos: a parte mais superficial, pior - pois isoladamente esse pensamento ocorre em palavras, quer dizer, em signos de comunicação, de onde se descobre a proveniência da consciência mesma. Em resumo, o desenvolvimento da linguagem e o desenvolvimento da consciência (não da razão, mas somente o tomar-consciência-de-si da razão) andam de mãos dadas" (FW/GC 354, KSA 3.592). 
se recorrer ao disfarce: "Todo espírito profundo necessita de uma máscara: mais ainda, ao redor de todo espírito profundo cresce continuamente uma máscara, graças à interpretação perpetuamente falsa, ou seja, rasa, de cada palavra, cada passo, cada sinal de vida que ele dá" (JGB/BM 40, KSA 5. 58).

Uma vez tornada um projeto pessoal, a filosofia de fachada provoca efeitos imediatos no leitor de Nietzsche, que se sente não só autorizado como impelido a compreender a filosofia nietzschiana como um tipo de filosofia esotérica. Num gesto semelhante àqueles que atribuem às doutrinas não escritas de Platão um maior valor do que para os diálogos, os leitores de Nietzsche podem supor que a sua verdadeira filosofia não está contida nas obras publicadas, uma vez que, descrente em relação à comunicação, o filósofo guardou para si os seus pensamentos mais profundos e complexos? Essa formulação fornece sustentação à famosa declaração de Heidegger: "O que o próprio Nietzsche publicou na sua época criativa foi sempre somente um primeiro plano (...) A autêntica filosofia de Nietzsche ficou relegada como "obra póstuma"".

Em suma, tratar os póstumos não como acessórios, mas como a principal fonte de onde emana o essencial do pensamento nietzschiano, pode ser encarado como a primeira grande consequência da filosofia de fachada9. Seja como for, eu gostaria de problematizar a hipótese esotérica - ou ao menos uma apresentação peculiar

7 Sobre essa comparação oportuna com os estudos platônicos, cf. DIXSAUT, M. Nietzsche, par-delà les antinomies, Lonrai: La Transparence, 2006, p. 11.

8 HEIDEGGER, M. Nietzsche I. Trad. Juan L. Vermal. Madrid: Destino, 2000, p. 24.

9 Muitos reagem com indignação a essa possibilidade, mas não raramente oferecendo argumentos frágeis. Tome-se o caso de Walter Kaufmann. Segundo o estudioso, "nenhum sério pesquisador preferiu as notas no lugar dos livros" (KAUFMANN, W., Nietzsche. Philosopher, Psychologist, Antichrist. Princeton: Princeton Univ. Press, 1974, p. 78). Recorre-se aí ao bom senso acadêmico. Posto que a tradição mostra que o bom senso dos pesquisadores os previne de dar maior relevância para o espólio do que para o material publicado, agir de outra maneira significaria ferir esse acordo tácito. Contudo, essa razão não passa de uma espécie de petitio principii. O que Kaufmann parece ter ignorado é que o fato de uma hipótese ser incomum e causar perplexidade não prova que ela esteja equivocada. 
dessa hipótese, pouco transigente com as aspirações dialógicas e dinâmicas que estão por detrás do projeto nietzschiano -, enquanto o único desfecho possível. Leituras como a de Heidegger supõem existir um absoluto estático, o que entra em direta contradição com um dos sustentáculos da filosofia de fachada: a inesgotabilidade da tarefa filosófica. Ademais, elas alimentam a ideia de que Nietzsche foi um incorrigível misantropo. Eu procurarei, a seguir, contestar de forma mais direta esse último ponto, retomando posteriormente o primeiro.

A seleção do leitor ideal.

No depoimento destacado acima, Nietzsche sugere que escreve para si e não para leitores. Acerca dessa afirmação, é possível circunscrever uma finalidade enviesada mediante a consulta de outras passagens em que o filósofo tematiza a sua relação com o leitor. Essa consulta revela que o que Nietzsche expressa é menos uma convicção de que é preciso manter em segredo a sua verdadeira filosofia do que uma constatação de sua extemporaneidade. Escrever para si decorre da ausência de leitores (nomeadamente os alemães ${ }^{10}$ ) que o saibam ler em sua época ${ }^{11}$; da ausência de "ouvidos e mãos" dos seus contemporâneos para as suas "verdades" (EH/EH, Por que escrevo livros tão bons 1, KSA 6. 298). Em hipótese alguma é o reflexo de um pensador absorto em fantasias misantrópicas. A rigor, Nietzsche quer poder acreditar que os seus livros não foram redigidos apenas para ele, "como às vezes parecia" (MA II/HH II Prólogo 6, KSA 2. 376). Em outras palavras, o filósofo escreve para

10 Nietzsche relata a existência de muitos leitores respeitáveis de suas obras - "verdadeiros gênios" - fora da Alemanha: "Em Viena, em São Petesburgo, em Estocolmo, em Copenhague, em Paris e Nova Iorque" (EH/EH, Por que escrevo livros tão bons 2, KSA 6. 301). Cf. também: EH/EH, O caso Wagner 3, KSA 6. 360.

11 Cf. Nachlass/FP 1883, 8[20], KSA 10. 341; Nachlass/FP 1882, 3[1]162, KSA 10. 72. 
o leitor, mas não para o leitor de sua época e, no limite, para qualquer leitor, o que seria somente sinal de um "livro ruim" (VM/OS 158, KSA 2. 618). "Todo espírito, todo gosto mais nobre escolhe para si os seus ouvintes, quando quer comunicar-se; ao escolhê-los, impõe limites 'aos outros"” (FW/GC 381, KSA 3. 633).

Eis uma proposta bastante peculiar: não são os leitores que escolhem o que leem, mas é o autor que escolhe por quem será lido. Nietzsche não quer ser lido pelos seus contemporâneos; não quer ser compreendido pelos "porcos eruditos e os gansos citadinos, os curadores, ou os 'jovens alemães', ou todos que bebem cerveja e fedem política" (Nachlass/FP 1886-1887 7[66] KSA 12. 320) - isso não só é desejável, como lhe parece justo ${ }^{12}$. O leitor de Nietzsche, a quem é permitido compreendê-lo, é aquele que sobrevive a um procedimento seletivo que, de resto, ocorre segundo leis criteriosas. É por meio das "leis mais sutis de um estilo" que se estabelece o afastamento dos leitores indesejados, proibindo-lhes a "entrada", compreensão", bem como a abertura dos ouvidos àqueles que ao filósofo são "aparentados" (FW/GC 381, KSA 3. 633). Tal como nos mostra Marton, "tudo se passa como se o estilo fosse um mot de passe, uma mensagem cifrada, uma senha. Apresentando-a, o autor lança sua isca; decifrando-a, o leitor dele se mostra digno"13. Não chega a causar espanto, nesse sentido, a indiferença com que Nietzsche recebe as sugestões oferecidas pelos eruditos da Universidade de Basel para que ele modifique a "forma literária" de seus escritos - na visão deles, a razão para que o filósofo não seja lido e conhecido ${ }^{14}$. O estilo nietzschiano dificulta a leitura para aqueles que perseguem o modelo grosseiro para o qual ler significa se submeter ao pensamento alheio ${ }^{15}$. Nietzsche não cultiva o menor interesse em ser um objeto de devoção de fanáticos ou um objeto

12 Cf. EH/EH, Por que escrevo livros tão bons 1, KSA 6. 298.

13 MARTON, S. Nietzsche, seus leitores e suas leituras. São Paulo: Barcarolla, 2010, p. 87.

14 Cf. Nachlass/FP 1888, 22[28], KSA 13. 596.

15 Cf. EH/EH, Por que sou tão esperto 3, KSA 6. 284. 
de análise de eruditos. O leitor que ele persegue, e cuja entrada o seu estilo permite, é aquele que "ainda não desaprendeu a pensar enquanto lê", que ainda "compreende o segredo de ler nas entrelinhas" (BA/EE Prólogo, KSA 1. 648). Nietzsche quer o leitor que saiba pensar junto, donde não se segue somente uma técnica, mas uma cumplicidade espiritual ${ }^{16}$.

Aforismo enquanto convite para a corrente de pensamentos.

Mas qual o estilo que pode ser considerado o mais apropriado para se selecionar esses leitores ideais? É tentador eleger imediatamente o estilo aforístico - o próprio Nietzsche se apresenta como um mestre do gênero, e a recepção da obra nietzschiana notoriamente a designou como essencialmente aforística no seu aspecto formal. Contudo, esse é um juízo precipitado que abrevia algumas dificuldades, respectivamente semânticas e históricas. Considerando-se a prevalência dos aforismos nos escritos nietzschianos do período médio e tardio ${ }^{17}$, é importante salientar que o antidog-

16 Cf. EH/EH, Por que sou tão sábio 3, KSA 6. 267; Por que escrevo livros tão bons 1 e 3, KSA 6. 298 e 302.

17 Poder-se-ia também dizer que existe alguma equivocidade a respeito da adesão de Nietzsche ao estilo aforístico. Tal como aponta de forma influente Nehamas, Nietzsche recorre aos aforismos unicamente nas obras do chamado período médio e a partes dos últimos escritos. Cf. NEHAMAS, A. Nietzsche: Life as Literature. London: Harvard Univ. Press, 1985, p. 18. Cabe destacar que esse tipo de abordagem conta com um importante aporte biográfico. Após a insistência do seu editor, desde 1881, para abandonar o gênero - pedido, num primeiro momento, rejeitado, posto que, como diz o filósofo a Gast, ele não tem outra escolha senão ser um Aphorismus-mensch que somente antevê relações -, Nietzsche finalmente parece ceder em 1883, quando, numa carta a Overbeck, revela que o seu Zaratustra é um "poema e não uma compilação de aforismos" (Carta para Franz Overbeck, dia $1^{\circ}$ de fevereiro de 1883, KSB 6.326). Essa notícia reverbera, e em abril do mesmo ano Overbeck compartilha com Fuchs a sua felicidade por Nietzsche ter abandonado o estilo, um estilo "infeliz" para livros provocadores. Cf. Carta de Franz Overbeck para Carl Fuchs, dia 15 de abril de 1883, KGB III 7/1. 935. Nessa mesma esteira, muitos outros estudiosos defenderão que o estilo literário dominante nas obras dos períodos médio e final seria o ensaio ao invés do aforismo. Entendendo-se aforismos como frases sucintas, então somente uma parte mínima dessas obras seria compatível com o gênero. 
matismo que comanda os propósitos da filosofia de fachada não são forçosamente inerentes a essa forma literária. Assim, torna-se imperioso empreender um exame de como Nietzsche recepciona o aforismo e de como ele o mobiliza para fins específicos.

É uma tarefa particularmente dispendiosa e incerta delimitar as exatas causas histórico-contextuais que levaram Nietzsche ao estilo aforístico. Uma explicação mais simples, e possivelmente também mais difundida, professa que a adesão do filósofo ao gênero é em larga medida um reflexo de sua relação com Paul Rée iniciada em 1873. Nesse período, Rée inicia as suas conversações com Nietzsche, apresentando-lhe os rascunhos de sua obra aforística que seria publicada anonimamente dois anos depois, Psychologische Beobachtungen, bem como escritos dos moralistas franceses que popularizam essa voga literária, especialmente La Rochefoucauld $^{18}$, influências determinantes para a composição de Humano,

Os escritos de Nietzsche são, em sua maior parte, extensos, apesar de descontínuos, donde a proximidade com o ensaio. Donnellan é categórico nessa direção: "Longe de imitar a propensão francesa para a expressão lógica mais breve possível de um pensamento, ele (Nietzsche) tende a ampliar a ideia original num retrato em miniatura ou num poema em prosa (...) Há no geral uma tendência em sacrificar a brevidade em nome da expressão de um pensamento em todas as suas nuances, resultando em pequenos ensaios ao invés de formulações epigramáticas" (DONNELLAN, B. Nietzsche and the French Moralists. Bonn: Bouvier Verlag Herbert Grundmann, 1982., p. 126). Contudo, há de se perguntar até que ponto existe uma diferença real entre aforismo e ensaio. Como diz Meyer em sua primorosa obra sobre o estilo alemão, "o aforismo numa medida aumentada é o ensaio". Isso ocorre porque o ensaio compartilha com o aforismo o caráter "sentencioso", tendo, como aquele, por finalidade, mais inspirar do que oferecer um conhecimento acabado, de modo que a única diferença entre ensaio e aforismo é que o primeiro deve ser acolhido enquanto um "sistema de sentenças (Sätzen)" (MEYER, R. Deutsche Stilistik. Muenchen: C.H. Beck'sche, 1906, p. 158).

18 Apesar de se tornarem grandes amigos somente a partir do final de 1875, Nietzsche já cultivava uma admiração intelectual por Rée desde 1873. Nesse período o filósofo é introduzido por Romundt a Rée, que estava em Basel. As impressões desse encontro são notadamente positivas, tal como se pode ler numa carta de Nietzsche para Rohde: "Um amigo de Romundt chegou aqui para ficar todo verão, um homem muito contemplativo e talentoso, um schopenhaueriano, chamado Rée" (Carta para Erwin Rohde, dia 5 de maio de 1873 KSB 4. 149). Dois anos mais tarde, após adquirir uma cópia de Psychologische Beobachtungen, Nietzsche escreve para Rée elogiando a sua recém-publicada obra aforística. Cf. Carta para Paul Rée, dia 22 de outubro de 1875, KSB 5. 122 e 123. Ainda sobre o início da relação entre Nietzsche e Rée, cf. SMALL, R., Nietzsche and Rée. A Star Friendship. Oxford: Oxford Univ. Press, 2007, pp. 3 - 21. 
demasiado humano, a primeira obra aforística de Nietzsche. Uma explicação alternativa poderia contrariar a validade absoluta da primeira, mostrando que, muito antes do encontro com Rée, Nietzsche se mostra um simpatizante do laconismo literário - ainda que o termo aforismo não apareça nesse momento, cumpre lembrar que o filósofo dá sinais de compreender essa designação em analogia com termos aparentados, como sentença, máxima, etc. ${ }^{19}$ - devido à sua admiração por Lichtenberg, conhecido por ser o fundador dos aforismos na Alemanha - Nietzsche, numa carta de 1867, retrata Lichtenberg como uma autoridade estilística ao lado de Schopenhauer e Lessing ${ }^{20}$ - , e, mais direta e enfaticamente, em decorrência da oportuna concordância com Jean Paul, de quem Nietzsche traz uma citação em A filosofia na idade trágica dos gregos para corroborar o valor do estilo breve de Heráclito ${ }^{21}$.

Mas, apesar das incertezas acerca das reais motivações histórico-contextuais, é menos arriscado circunscrever os interesses formais que conduziram Nietzsche ao gênero num primeiro momento, sendo o principal a clareza. Sobre esse ponto, pode-se ler num póstumo de 1876: "Deve-se evitar longos períodos: ou, se eles forem necessários, julgá-los de forma puramente lógica (...) Clareza é a primeira exigência" (Nachlass/FP 1875 - 1879, 15[2], KSA 8. 279). Essa hesitação em relação à prolixidade já se faz notar na defesa do estilo lacônico de Heráclito em 1873, a quem Nietzsche vê, dentre todos os homens, como o escritor "mais claro e mais luminoso" (PHG/FIT 7, KSA 1. 832). Todavia, não se deve encarar a clareza do estilo lacônico em forçoso antagonismo à obscuridade. A obscuridade é preservada, afetando uma classe específica de leitores:

19 Vale destacar que, assim, Nietzsche está na esteira da tradição alemã que faz uso do aforismo sem se preocupar em separá-lo de outras modalidades lacônicas. Lichtenberg, por exemplo, usa Sentenz, Maxime, Bemerkung, Idee e Gedanke como sinônimos. A esse respeito, cf. SPICKER, F. Der Aphorismus. Begriff und Gattung von der Mitte des 18. Jahrhundert bis 1912. Berlin/New York: Walter de Gruyter, 2007, pp. 62 e 182.

20 Cf. Carta para Carl von Gersdorff, dia 6 de abril de 1867, KSB 2. 209.

21 Cf. PHG/FT 7, KSA 1. 833. 
Nasser, E.

os leitores apressados. Como diz o filósofo, um estilo lacônico como o de Heráclito só é "obscuro para leitores apressados" (PHG/FIT, 7, KSA 1. 832). A obscuridade inerente a expressões breves é, assim, um valor relativo, funcionando como um mecanismo seletivo. Afastam-se os leitores medíocres que, como diz Jean Paul na citação evocada por Nietzsche, são obrigados a desistir de seu hábito de traduzir palavras profundas para a sua linguagem de todos os dias ${ }^{22}$. $\mathrm{E}$ isso porque a qualidade da clareza, que deve estar contida em expressões breves como aforismos e sentenças, não coincide com a completude. Homens apressados, como os homens modernos, que "rolam como pedra, conforme a estupidez da mecânica" (MA I/ HH I 283, KSA 2. 231), que carecem de tranquilidade, de tempo para pensar, estimam unicamente fórmulas acabadas. Aforismos e sentenças, porém, exigem um outro tipo de homem, afeito ao otium e à vita contemplativa ${ }^{23}$.

A esse respeito é preciso, antes de tudo, enfatizar o antidogmatismo subjacente aos aforismos e sentenças em Nietzsche, algo que o coloca numa senda específica. No que pode ser classificado de a geração aforística alemã que surge nos séculos XVIII e XIX, fortemente influenciada pela tradição hipocrática e pelos moralistas franceses, existem ramos com aspirações educacionais e religiosas que recorrem aos aforismos de maneira expressamente dogmática. É nessa direção que Heinrich Zedler designa os aforismos enquanto recitações de verdades; é na mesma esteira que o padre Joseph Holl considera apresentações breves como formas mais eficazes para se

22 "Jean Paul traz um bom ensinamento no tocante à brevidade: 'Em geral, é bom que tudo o que seja grande - tudo o que tenha sentido para grandes espíritos - se exprima em termos breves e (portanto) obscuros, para que os espíritos medíocres antes vejam aí um não-sentido do que o traduzam para a sua insipidez. Pois os espíritos vulgares têm a habilidade odiosa de só verem, nas palavras mais profundas e mais ricas, a sua própria opinião de todos os dias"” (PHG/FT 7, KSA 1. 833).

23 Sobre a distinção entre o homem ativo e o homem contemplativo, cf. MAI/HHI 283 286, KSA 2. 231 - 233. Sobre o aforismo enquanto instrumento para a vita contemplativa em Nietzsche, cf. VOEGELIN, E., "Nietzsche and Pascal" in: Nietzsche Studien 25, 1996, p. 137.

46 I Cad. Nietzsche, São Paulo, v.I n.35, p. 33-56, 2014. 
transmitir verdades ${ }^{24}$. Mais próximo de Nietzsche, Schopenhauer, no seu Aphorismen zur Lebensweisheit, recorre ao gênero enquanto uma forma atemporal e normativa; enquanto uma maneira de apresentar regras de vida em um caráter doutrinal ${ }^{25}$. É certo que Nietzsche também mobiliza os aforismos e sentenças com fins formadores e, nesse terreno, eles podem ter efeitos normativos. Contudo, esse uso é próspero unicamente para um público irrecuperável que não toleraria ter a sua inocência corrompida e que, ainda assim, deve ser convertido. Ao fazer um balanço do valor da brevidade impresso aos seus escritos, diz Nietzsche que essa é a forma ideal apara afetar "asnos e solteironas", arrebatando-os, elevando-os, encorajando-os a "serem virtuosos" (FW/GC 381, KSA 3. 635). Já para um público seleto, os aforismos não devem ser recebidos enquanto verdades que almejam efeitos prescritivos, mas descrições e partes de um processo - algo como fragmentos em sua acepção blanchotiana ${ }^{26}$.

Uma primeira informação significativa é, assim, que essas modalidades lacônicas não depõem a favor de um atomismo expressivo - fosse assim, Nietzsche seria ele mesmo uma vítima do que julga ser um estilo decadente ${ }^{27}$. Uma maneira de se apreender esse aspecto relacional encontra-se num patamar cético, quando se toma os aforismos enquanto referências a um nível pré-discursivo do pensamento carente de verdades últimas.

24 Cf. SPICKER, F. Op. cit., pp. 26 e 164.

25 Idem, Ibidem, pp. 132 e 336.

26 Para Blanchot, o aforismo denota completude - o que é corroborado através de um exame etimológico da palavra - enquanto o fragmento está vinculado à mobilidade da experiência. Justamente por essa razão Blanchot vê Nietzsche enquanto um escritor fragmentário ao invés de aforístico. Cf. BLANCHOT, M. L'entretien infini. Paris: Gallimard, 2012, pp. 228 e 229.

27 "No momento me deterei apenas na questão do estilo. - Como se caracteriza toda décadence literária? Pelo fato de a vida não mais habitar o todo. A palavra se torna soberana e pula fora da frase, a frase transborda e obscurece o sentido da página, a página ganha vida às expensas do todo - o todo já não é mais um todo. Mas isto é uma alegoria para todo estilo da décadence: a cada vez, anarquia de átomos, desagregação da vontade, 'liberdade individual', em termos morais - estendendo à teoria política, "direitos iguais para todos"” (WA/CW 7, KSA 6. 27). 
Nasser, E.

Em livros aforísticos como os meus há entre e por detrás dos curtos aforismos longas correntes de coisas e pensamentos estritamente ocultas; e alguns dentre eles podem ser duvidosos o suficiente para Édipo e a sua esfinge. (Nachlass/FP 1885, 37[5] KSA 11. 579).

O aforismo não é uma partícula isolada e independente, sendo, antes, o cume de uma cadeia de pensamentos - não são flashs de observação como em La Rochefoucauld ${ }^{28}$. Repetindo a apreciação disseminada por adeptos do estilo na Alemanha, Nietzsche determina que "algo que é dito brevemente pode ser o produto e colheita de algo que foi muito longamente pensado", e que é somente o leitor novato que encara os ditos breves como "algo de embrionário" (VM/OS 127, KSA 2. 609) ${ }^{29}$. Os aforismos devem ser tratados como epifenômenos, assim como tudo o que chega à consciência. Somente chega à consciência "as últimas cenas de conciliação e ajuste de contas" de um "longo processo" (FW/GC 333, KSA 3. 559); "tudo o que chega à consciência é a última conexão de uma corrente, uma conclusão" (Nachlass/FP 1885 - 1887, 1[61], KSA 12. 26). Mas, diferentemente dos habituais epifenômenos, os aforismos impedem a consciência de se autoalienar, exigindo que se percorra o caminho inverso: da perenidade do signo para a produção incessante de sentido.

Tal desvelamento inicia o rompimento entre forma e conteúdo. E isso porque a eficácia de uma forma como o aforismo não está, para Nietzsche, na sua capacidade expressiva. O que ocorre é praticamente o inverso: trata-se de uma modalidade literária mais vantajosa por realçar os limites da expressão, e, assim, a ausência de

28 Sobre a diferença entre os aforismos nietzschianos e as maximes de La Rochefoucauld, cf. DONNELLAN, B. Op. cit, p. 130.

29 Em 1880, Ebner-Eschenbach define o aforismo enquanto "o último toque de uma longa cadeia de pensamentos". Cf. SPICKER, F. Op. cit., p. 173. Goethe já havia dito algo semelhante: "Toda verdadeira visão sumária (Aperçu) surge como uma consequência e provoca consequência. É um membro intermediário de uma corrente maior, produtiva, ascendente" (GOETHE, J.W. Maximen und Reflexionen. Weimar: Goethe-Gesellschaft, 1907, p. 82.).

48 I Cad. Nietzsche, São Paulo, v.I n.35, p. 33-56, 2014. 
sentidos absolutos - "se a forma é fluída, o "sentido" é mais ainda" (GM/GM 12, II, KSA 5. 315). Com o laconismo, Nietzsche está reiterando de maneira radical a sua crítica da linguagem, apontando para o domínio do pensamento que precede os signos e que não pode ser esgotado por eles. Isso ocorre porque Nietzsche soube reconhecer a dimensão fluída, autêntica, do pensamento. Tal como eu já procurei mostrar, desde 1873 o filósofo professa uma visão radicalmente antieleata do pensamento: o pensamento está imerso na realidade do vir-a-ser, que antecede as representações ${ }^{30}$, o que contradiz a convicção em operações puramente lógicas, abstratas e atemporais das mentes geométricas das quais falava Pascal ${ }^{31}$.

Assim, aforismos e sentenças possuem uma serventia específica, respectivamente para o escritor e para o leitor. Para o escritor, serve para que ele tome consciência-de-si na sua facticidade; para que ele se recorde que "o efetivo investigador (Forscher) não deve 'falsificar', com um falso arranjo de dedução e dialética, as coisas e os pensamentos a que chegou de maneira diferente (...) não se deve perverter e dissimular ofato de como os nossos pensamentos nos chegaram" (Nachlass/FP 1885, 35[31], KSA 11. 522). Trata-se do momento em que se revela o procedimento indutivo que regula a relação entre experiência e linguagem ${ }^{32}$. Para o leitor, serve como um estimulante para se mergulhar na corrente do pensamento em sua processualidade; para que ele assimile a Versuch enquanto uma exigência primordial. Possivelmente inspirado pelo aforismo

30 Cf. NASSER, E. Epistemologia e ontologia em Nietzsche à luz do problema do tempo. Tese de doutorado, 2013, pp. $46-64$.

31 Como bem destaca Krüger, o aforismo só pode ser entendido como a "forma necessária" do pensamento de Nietzsche quando se elucida que ele interpreta o mundo "não como algo entificado (Seiendes), mas como algo em vir-a-ser" (KRÜGER, H. Über den Aphorismus als philosophische Form. München: Edition Text + Kritik, 1988, p. 97).

32 Convém recuperar aqui o que diz Groarke a respeito dos aforismos de Pascal: "O pensamento aforístico é indutivo, não por ser um tipo específico de argumento e nem por apresentar uma reivindicação geral (...), mas por fazer a ponte entre experiência e linguagem" (GROARKE, L. "Philosophy as Inspiration: Blaise Pascal and the Epistemology of Aphorisms" in: Poetics Today, 28:3, 2007, p. 433). 
Nasser, E.

de Rée que abre Psychologische Beobachtungen, diz Nietzsche: “A sentença é um membro de uma cadeia de pensamentos; ela requer que o leitor reconstrua essa cadeia por seus próprios meios" (Nachlass/FP 1876 - 1877, 20[3], KSA 8. 361) ${ }^{33}$. Por esse motivo, a sentença ou aforismo inaugura o momento do estado meditativo, da vita contemplativa, no leitor. Esse estímulo encontra a sua causa na incompletude que caracteriza expressões lacônicas, pois enquanto "membros" de algo mais vasto, incita a participação do leitor. Ao contrário do completo, que tem "efeito debilitante" (MAI/HDI 199, KSA 2.167), o incompleto "deixa-se mais a fazer para quem observa, ele é incitado a continuar elaborando o que lhe aparece tão fortemente lavrado em luz e sombra, a pensá-los até o fim e superar ele mesmo o obstáculo que até então impedia o desprendimento completo" (MAI/HDI 178, KSA 2.162).

Nietzsche fornece, com os aforismos, experimentos do pensamento, supondo que, com a participação do leitor, eles evoluam. $\mathrm{O}$ filósofo não seria possuidor de um corpo de doutrinas fixas ou de convicções - a não ser enquanto meio, i.e., enquanto hipótes ${ }^{34}$. É somente nesse horizonte cético que a cumplicidade com o leitor ideal se faz compreensível e imprescindível. Nele, o leitor não é um mero receptor de convicções, mas aquele a ser inspirado pela dissuasão. O efeito mais determinante dos aforismos nietzschianos sobre os leitores deveria ser o de transportá-los para o reino das opiniões. Se filosofa, então, de uma nova forma: possuindo opiniões como peixes num viveiro, i.e., saindo "para pescar e ter sorte então temos nossos peixes, nossas opiniões" (WS/AS317, KSA 2.693).

33 "Sentenças são extratos do pensamento que todos podem expandir de acordo com o próprio gosto" (RÉE, P. Psychologische Beobachtungen. Aus dem Nachlass vom. Berlin: Carl Duncker, 1875, p. 3).

34 Apesar de Nietzsche ser o autor da conhecida expressão “convicções são prisões", ele não deixa de admitir, de uma forma moderada, o uso de convicções, a saber, enquanto "meio" (AC/AC 54, KSA 6.236). Como bem aponta Kaufmann, tratar-se-ia de um uso das convicções enquanto hipóteses. Cf. KAUFMANN, W. Op. cit., p. 92. Ainda sobre o uso de hipóteses, e a hesitação de Nietzsche frente a afasia cética, cf. NASSER, E. Op. cit, pp. 140 - 149.

50 I Cad. Nietzsche, São Paulo, v.I n.35, p. 33-56, 2014. 


\section{Trata-se, em poucas palavras, da "filosofia das 'aspas" (Philosophie der "Gänsefuisschen"), a filosofia que contempla não as formas eter- nas, mas o universo dinâmico em que a cabeça é atravessada pelo fluxo de "toda espécie de pensamentos, preocupações e coisas preo- cupantes" (Nachlass/FP 1885, 37[5], KSA 11. 579) ${ }^{35}$.}

35 Esse efeito provocado pelo estilo aforístico sobre a concepção nietzschiana de filosofia subsidia novas questões. Afinal de contas, em que medida esse ousado experimento formal não implica uma decisão filosófica temerária? Sendo um produto dos aforismos, a filosofia das aspas, uma filosofia de opiniões, não abala a própria concepção de filosofia? Não foram poucos, afinal, os que colocaram em suspeita as credenciais filosóficas de Nietzsche justamente em virtude do gênero heterodoxo de apresentação do seu pensamento, distante dos habituais procedimentos dedutivo e dialético. Sobre Nietzsche e os seus aforismos, diz Johannes Schlaf: "Ele também não foi especialmente um grande filósofo. Ele perde antes a filosofia num malabarismo sumarizante, aforístico" (Cf. KRUMMEL, R.F. Nietzsche und der deutsche Geist, II. Berlin/New York: Walter de Gruyter, 1998, p. 173). Os aforismos não seriam, como diz ainda Riehl a respeito da problemática escolha estilística de Nietzsche, "o grande estilo arquitetônico de grandes construtores e criadores" (RIEHL, A. Nietzsche. Der Künstler und der Denker. Stuttgart: Frommann's Verlag, 1898, p. 22). Foi muito provavelmente devido a tal concordância acerca do antagonismo essencial entre aforismo e filosofia que se proliferaram explicações frívolas para os motivos da adesão de Nietzsche ao estilo: desde a necessidade imposta pelas suas dores de cabeça para se expressar com brevidade até os desejos irrefreáveis de uma personalidade excessivamente individualista e pretensiosa. Bem entendido, enfim, o que está sendo dito é que Nietzsche não pode pleitear um lugar na galeria dos filósofos ilustres por ser um adepto do pensamento antidogmático, antissistemático. Naturalmente essa espécie de juízo padece do ônus da parcialidade, trazendo consigo premissas bastante pronunciadas sobre os fins da filosofia, o que exigiria o início de uma digressão demasiadamente monumental para o presente artigo. $\mathrm{O}$ que se pode dizer com alguma segurança é que a identidade filosófica de um filósofo não é ameaçada devido aos seus momentos mais iconoclastas, críticos, céticos - a ideia de sistema não está forçosamente contida na definição de filosofia, salvo em momentos isolados da história que requerem uma apreciação particular (como no caso do entrelaçamento entre filosofia e hegelianismo na primeira metade do século XIX). Assim, Nietzsche conta trazer uma filosofia com os aforismos, mas não uma filosofia na acepção de dogmáticos e sistemáticos - antes de tudo o aforismo é aqui uma forma filosófica. Nesse sentido, talvez a sua acepção de filosofia deva ser encontrada entre dois grandes eventos intelectuais que marcam a demolição do pensamento sistemático: o combate ao filisteismo dos sistemáticos, empreendido pelos românticos, em nome da infinitude da tarefa filosófica e a redefinição da concepção de ciência, e com ela a de filosofia, imposta pelas ciências empíricas, i.e., a ciência enquanto um agregado de conhecimentos mutáveis que encontra o seu referencial no experimentalismo ao invés da ciência como conhecimento apodítico dos universais. Poder-se-ia dizer que a traditio per aphorismus em detrimento da traditio methodica - para usar a clássica distinção de Bacon no seu combate ao sistema dos escolásticos -, abriga com justeza as exigências desses rumos antissistemáticos da filosofia, que são também os rumos da filosofia nietzschiana. 
Isso não quer dizer, enfim, que Nietzsche, com os aforismos, pretenda tão somente exortar a livre imaginação dos seus leitores. O que previne esse desenlace é a exigência da leitura filológica em paralelo com a interpretação. Como vimos, a filologia é evocada enquanto uma forma de conter os excessos interpretativos, de modo que não se deve dissolver simplesmente a literalidade do texto em nome da interpretação criadora. A interpretação torna-se sinônimo de desonestidade quando há "falta de filologia", i.e., quando ela se torna um impedimento para "ler o texto enquanto texto" (Nachlass/FP, 15[90], KSA 13. 458). Não moderar a interpretação através da filologia conduz a resultados indesejados; dispensar a filologia faz com que se resista ao aspecto receptivo que está contido na definição de aforismos, dilacerando, assim, a letra do filósofo. Foi justamente nessa via que Nietzsche condenou os seus contemporâneos que acreditavam tê-lo compreendido. "Quem acreditou ter compreendido algo de mim", diz Nietzsche, "caracterizou-se, à sua imagem, como algo extraído de mim - não raramente como a contraposição (Gegensatz) a mim mesmo" (EH/EH, Por que escrevo livros tão bons 1, KSA 6. 298). Foram interpretações exageradamente livres que montaram articulações equivocadas com os conceitos nietzschianos - como a associação entre darwinismo e além-do-homem. Nietzsche espera que, com os aforismos, os seus escritos sejam interpretados, sem que isso seja entendido como uma autorização para que eles sejam obliterados. É certo que a verdade de sua filosofia não está dada - o que pressupõe o dogmatismo do texto e a interrupção do fluxo de pensamentos -, mas também não é uma verdade relativa passível de ser repartida entre múltiplos pontos de vista divergentes. Temos, portanto, uma antinomia ${ }^{36}$ que, contudo,

36 Dixsaut nos oferece uma formulação interessante para essa antinomia: "Nós podemos traduzir assim a antinomia perturbadora e subterrânea que Nietzsche teria posto: a afirmação que tudo é interpretação abole o texto em nome de um relativismo integral, enquanto aquela que põe um texto independente de suas interpretações corre o risco de erigir esse texto numa norma exterior e absoluta, donde se segue o risco de dogmatismo" (DIXSAUT, M. Op. cit., p. 101). 
não é absolutamente insuperável se se problematiza o caráter radical da oposição. Em outras palavras, o leitor filólogo e o leitor intérprete devem coexistir numa relação de tensão intransponível. É justamente a irredutibilidade dessa tensão que impede o leitor de se submeter tanto ao dogmatismo do texto quanto ao relativismo das interpretações.

\section{Conclusão}

O que significam, enfim, as coordenadas apresentadas por Nietzsche aos seus leitores? Deveriam elas ser traduzidas como um tipo de método? Não poderíamos simplesmente dizer que se trata do método estrategicamente formulado por Nietzsche para os seus discípulos? De forma irrestrita, não. A razão para tanto está na própria esperança hermenêutica que move, em grande medida, a elaboração dessas coordenadas. Lembremo-nos que a consciência metodológica que se instala na modernidade é alimentada pelo ideal do conhecimento objetivo que nos fornece certezas. O propósito é estabelecer um caminho tão seguro que, mesmo que percorrido incontáveis vezes, nos conduzirá a resultados idênticos. Ora, é justamente esse ideal que Nietzsche está aqui combatendo. A sua meta não é apresentar o caminho seguro para se alcançar objetivamente as suas verdades. O filósofo lança mão de um empreendimento seletivo que só admite a chegada de leitores que não estão em busca de verdades absolutas e estáticas; um empreendimento que convoca o leitor espirituoso, aquele capaz de se entusiasmar com a tarefa do pensamento inesgotável. Dessa forma, pode-se dizer que o seu intuito com tais condições é afugentar o leitor domesticado por ideais metodológicos. Por outro lado, a incorporação da consciência hermenêutica por parte do leitor não deve ser entendida como uma completa diluição da objetividade. Como vimos, Nietzsche também solicita o leitor filólogo, aquele que retém algo da mentalidade positivista. 
Assim, a figura do leitor ideal de Nietzsche é ambígua, de tal modo que a possibilidade de se encontrar aí a concentração de desejos contraditórios provindos do filósofo não pode ser descartada de forma definitiva. Mas essa parece ser uma alternativa demasiadamente frágil que subestima uma trama mais sofisticada. Tudo leva a crer que Nietzsche realmente pretendia criar um contexto para a recepção de sua obra imune a leituras dogmáticas e relativistas, de modo que a leitura bem-sucedida dos seus textos, ao menos aqueles que se podem classificar de aforísticos, seria aquela que recorre, simultaneamente, à filologia e interpretação. Não proceder dessa forma faria com que se perdesse o que foi ocultado na demonstração - caso se priorize a literalidade do texto - ou o que está sendo dito no texto - caso se conceda exclusividade à operação interpretativa.

Por fim, ressalto que não pretendo apresentar um manual de como ler Nietzsche. É possível que leituras que ignorem essas coordenadas tenham êxito, como obviamente já tiveram, oferecendo contribuições estimulantes para os estudos nietzschianos. O meu ponto é unicamente realçar que desprezar essas coordenadas pode deixar o leitor de Nietzsche mais vulnerável às armadilhas constitutivas ao estilo do filósofo.

\begin{abstract}
During practically all of his philosophical itinerary, Nietzsche was concerned with the reception of his thought, developing coordinates on how he would like his writing to be read. These coordinates acquire a significant and strategic role particularly during the period in which the philosopher conceived the project of a resolute concealment of his most essential positions - a project that will pair with his adhesion to an aphorismic style - that can be divided in two classes: those that requests the reader that preserves the text literacy and those that incites the reader to undertake an art of interpretation. The gathering of these two directions generates the figure of the ideal reader of Nietzsche, a reader that actively enters the chain of thought that precede the aphorisms, without, however, loosing site of the philosopher's word.
\end{abstract}

Keywords: reader - reception - philology - interpretation - aphorism

54 I Cad. Nietzsche, São Paulo, v.I n.35, p. 33-56, 2014. 


\section{referências bibliográficas}

BICKEL, E. Friedrich Ritschl und der Humanismus in Bonn: ein Beitrag zur Neugestaltung der höheren Schule in der Nord-Rheinprovinz. Bonn: Hans Scheur, 1946.

BLANCHOT, M. L'entretien infini. Paris: Gallimard, 2012.

DIXSAUT, M. Nietzsche, par-delà les antinomies. Lonrai: La Transparence, 2006.

DONNELLAN, B. Nietzsche and the French Moralists. Bonn: Bouvier Verlag Herbert Grundmann, 1982.

GERBER, G. Die Sprache als Kunst. Berlin: R. Gaertners, 1885.

GOETHE, J.W. Maximen und Reflexionen. Weimar: Goethe-Gesellschaft, 1907.

HEIDEGGER, M. Nietzsche I. Trad. Juan L. Vermal. Madrid: Destino, 2000.

KAUfMAnN, W. Nietzsche. Philosopher, Psychologist, Antichrist. Princeton: Princeton Univ. Press, 1974.

KRÜGER, H. Über den Aphorismus als philosophische Form. München: Edition Text + Kritik, 1988.

KRUMMEL, R.F. Nietzsche und der deutsche Geist, II. Berlin/New York: Walter de Gruyter, 1998.

MARTON, S. Nietzsche, seus leitores e suas leituras. São Paulo: Barcarolla, 2010.

MEYER, R. Deutsche Stilistik. Muenchen: C.H. Beck'sche, 1906.

NASSER, E. Epistemologia e ontologia em Nietzsche à luz do problema do tempo. Tese de doutorado (USP), 2013.

NEHAMAS, A. Nietzsche: Life as Literature. London: Harvard Univ. Press, 1985.

NIETZSCHE, F. Sämtliche Werke. Kritische Studienausgabe. Berlin/New York: Walter de Gruyter, 1999.

. Werke. Kritische Gesamtausgabe. Berlin/New York: Walter de Gruyter, 1969.

. Sämtliche Briefe: Kritische Studienausgabe. Berlin/ New York: Walter de Gruyter, 1986.

. Nietzsche Briefwechsel. Kritische Gesamtausgabe. Berlin/New York: Walter de Gruyter, 1975.

RÉE, P. Psychologische Beobachtungen. Aus dem Nachlass vom. Berlin: Carl Duncker, 1875

RIEHL, A. Nietzsche. Der Künstler und der Denker. Stuttgart: Frommann's Verlag, 1898.

SMALL, R. Nietzsche and Rée. A Star Friendship. Oxford: Oxford Univ. Press, 2007.

SPICKER, F. Der Aphorismus. Begriff und Gattung von der Mitte des 18. Jahrhundert bis 1912. Berlin/New York: Walter de Gruyter, 2007.

VOEGELIN, E. "Nietzsche and Pascal” in: Nietzsche Studien 25, 1996.

Cad. Nietzsche, São Paulo, v.I n.35, p. 33-56, 2014. $\quad \mathbf{5 5}$ 
Nasser, E.

VOGT, E. "Der Methodenstreit zwischen Hermann und Böckh und seine Bedeutung für die Geschichte der Philologie". In: FLASHAR, H., GRÜNDER, K., HORSTMANN, A. (Orgs.). Philologie und Hermeneutik im 19. Jahrhundert. Zur Geschichte und Methodologie der Geisteswissenschaften. Göttingen: Vandenhoeck \& Ruprecht, 1979.

Artigo recebido para publicação em 18/12/2013.

Artigo aceito para publicação em 02/02/2014.

56 I Cad. Nietzsche, São Paulo, v.I n.35, p. 33-56, 2014. 